\section{Long-term outcome of child- hood acute myeloid leukemia: A 10-year retrospective cohort study}

\author{
Tran Kiem Hao, Chau Van Ha, \\ Nguyen Huu Son, Pham Nhu Hiep \\ Pediatric Center, Hue Central Hospital, \\ Hue, Vietnam
}

\section{Abstract}

Acute Myeloid Leukemia (AML) in children is a serious disease. With a proper treatment, a long-term survival rate above $50 \%$ is typical. Before 2010, all the AML patients died in our hospital, and abandonment rate was more than $50 \%$. The aims of this study are to explore the long-term outcome of newly childhood acute myeloid patients treated at Hue Central Hospital from 2010 to 2019.A retrospective study was conducted on 98 children with AML who admitted Hue Central Hospital from January 2010 to December 2019. The diagnosis was confirmed by morphological FAB criteria, cytochemistry and immunophenotype. Patients were treated with using modified AML 7-3 Regimen. Social supports were provided to patients/families. A total of 98 children with AML were analyzed with mean age of 5.6 years ranging from 3 months to 15 years. The male to female ratio was $1.8: 1$. The overall complete remission rate after induction were $82.6 \%$. Patients accounted for 46 $(46.9 \%)$ had relapses which occurred in during chemotherapy $n=27(27,6 \%)$, after finishing chemotherapy $\mathrm{n}=19(19,4 \%)$. Overall survival at 3 years were $23.2 \%$. The event-free survival at 3 years were $20.2 \%$. Abandonment cases were 4 (4.1\%). During the period study, abandonment has been reduced successfully with holistic strategies such as financial support, managing family group, providing education, early follow-up of patients who missed appointments and free accommodation near hospital for patients/families. However, with a high rate patient achieved complete remission after induction phase $(82.6 \%)$, but the overal survival and event-free survival at 3 years were still low in my hospital (23.2 \% and 20.2\% respectively). It reflected that it was very difficult to treat successfully AML in lowand middle-income countries. We are considering the way how to improve the quality treatment for childhood acute myeloid leukemia in my hospital.

\section{Introduction}

Acute myeloid leukemia (AML) is a clonal disease of the hematopoietic tissue, characterized by abnormal proliferation of myeloid progenitor cells, resulting in insufficient generation of normal mature blood cells. ${ }^{1}$ AML accounts for approximately $25 \%$ of pediatric leukemia worldwide. ${ }^{2,3}$

The dramatic improvement of outcomes in pediatric AML over the last 3 decades has been achieved with intensification of chemotherapy, improvements in supportive care, wider application of various hematopoietic stem cell transplantations, recent advances in stratification into risk groups based on cytogenetics and more recently on molecular genetics, and early response evaluation by minimal residual disease. ${ }^{3-5}$ Currently, the overall survival (OS) in pediatric AML patients ranges from $60-70 \% .^{2,6}$

Currently, the likelihood of AML cure in developed countries is around $60 \% .^{1} \mathrm{In}$ Vietnam, treatment for children with AML remains difficult which is carried out in some oncology hospitals. The treatment protocols were not similar among hospitals. The outcome was poor with lots of cases are not received full treatment or even abandonment.

Since 2008, Pediatric Center of Hue Central Hospital applied the protocol AML73 for treatment of children with AML. In this study, we report the long-term outcome of childhood AML treated by protocol AML7-3 in our center.

\section{Materials and Methods}

From December 2010 to December 2019, ninety-eight newly diagnosed patients with AML under 16 years of age were admitted to Pediatric Center of Hue Central Hospital. The diagnosis of AML were based on morphology, cytochemistry, and immunophenotyping by flow cytometry of bone marrow aspirate and/or peripheral blood, performed with EuroFlow 8-color antibody panels (EuroFlow-ESLHO, Rotterdam, NL) (Table 1). The minimal residual disease was analyzed by flow cytometry in the bone marrow after 21 days of induction treatment. The treatment protocols used were AML7-3 (Table 2).

Medical records were retrospectively reviewed on demographic findings such as age, sex, white blood cell (WBC) count at diagnosis, morphologic, cytogenetic, and molecular classification of AML. Remission induction rate, overall and eventfree survival rate, and causes of deaths were analyzed.
Corresponence: Tran Kiem Hao, Pediatric Center, Hue Central Hospital, 16 Lê Lợi, Vĩnh Ninh, Thành phố Huế, Thừa Thiên Huế, Vietnam.

E-mail: trankiemhaobvh@yahoo.com

Key words: Childhood acute myeloid leukemia, treatment, outcome.

Contributions: The authors contributed equally.

Conflict of interest: The authors declare no potential conflict of interest

Availability of data and materials: Data available upon reasonable request to the authors.

Ethics approval and consent to participate: The present study was approved by the Institutional Review Board of Hue Central Hospital under the reference number of 12122019/HCH.

Informed consent: Informed consent not needed since it is a retrospective study.

Received for publication: 2 February 2020

Revision received: 19 February 2020.

Accepted for publication: 19 February 2020.

This work is licensed under a Creative Commons Attribution NonCommercial 4.0 License (CC BY-NC 4.0).

(C) Copyright: the Author(s), 2020

Licensee PAGEPress, Italy

Pediatric Reports 2020; 12:8486

doi:10.4081/pr.2020.8486

Overall survival (OS) was defined as the time between diagnosis and death from any cause or time of last contact. Event-free survival (EFS) was calculated from the date of diagnosis to last follow-up or first event (failure to achieve remission, relapse, second malignancy or death due to any cause, whichever occurred first). Continuous variables were expressed as mean \pm standard deviation; categorical variables were expressed as numbers and percentages. Probabilities of survival were estimated using the Kaplan-Meier method. P-value $<0.05$ was considered statistically significant. The software package SPSS version 21.0 (SPSS Inc, Chicago, IL, USA) was used for all statistical analyses.

\section{Results}

A total of 98 childhood acute myeloid patients were diagnosed for 10 years (20102019). Patient characteristics of children with AML by study periods are shown 
in Table 3. Sixty-three patients $(64.3 \%)$ were males (male/female ratio, 1.8:1). The mean age at diagnosis was 5.56 years (range, 3 mo to $15 \mathrm{yr}$ ). Age distribution was: $£ 1$ years, $11.2 \%$; 2-9 years, $63.3 \%$; and $\geq 10$ years, $25.5 \%$. A half of cases come from Thua Thien Hue and Quang Tri province. The mean WBC count at diagnosis was $47.24 \pm 90.69\left(\times 10^{9} / \mathrm{L}\right)$. The most common subtype as per the FAB classification was AML M2.

At the end of the first cycle, there were $62.2 \%$ patients achieved a complete remission, $13.5 \%$ had a partial response, and $13.5 \%$ were resistant. For those who did not achieve remission, we continued to provide chemotherapy. Of those in partial remission or resistant after the induction phase achieved a complete remission with a subsequent therapy was 20 cases $(76.9 \%)$. Thus, a total of $82.6 \%$ achieved a complete remission. There were $11.2 \%$ pattients passed away during the first cycle. There were $27.6 \%$ relapsed during chemotherapy, $19.4 \%$ relapsed after finish treatment. There were $4.1 \%$ patients refused treatment (Table 4). The 3-year OS and EFS rate for the whole cohort were $23.2 \%$ and $20.2 \%$, respectively (Figures 1 and 2).

\section{Discussion}

Like in other studies, male sex was slightly predominant, and most patients were older than 2 years (Table 3). ${ }^{7}$ The most prevalent morphological type was FAB M2 $(42.9 \%)$, which was in close agreement with previous studies.7,8 The FAB morphological classification for AML can define treatment and risk group stratification. Chromosomal abnormalities in AML include aberrations described as gain or loss of whole chromosomes structural abnormalities or balanced translocations. The literature reports that the translocation $\mathrm{t}(8 ; 21)$ is the most prevalent, varying between $12 \%$ and $23 \%$ whereas $t(15 ; 17)$ is observed in $3.4-10 \%$ of cases. ${ }^{9}, 10$ According to Sandahl JD, abnormal karyotypes were present in 452 cases $(76 \%)$ and numerical aberrations were present in $40 \%$ $(n=237)$ of all pediatric AML. 11

In this study, the 3-year OS and EFS were $23.2 \%$ and $20.2 \%$, respectively, for 2010-2019 (Figures 1 and 2). This rate was lower than that of developed countries such as Japan $(75 \%),{ }^{2}$ Europe $(69 \%)^{12}$ and the United States (64\%), ${ }^{6}$ and lower compared with that of developing countries in Asia, such as China (7-yr OS, 33\%)13 and Thailand (5-yr OS, 35\%) ${ }^{14}$ (although the study periods and follow-up durations were slightly different among these studies). These disparities may be caused by multiple

Table 1. AML immunophenotyping.

\begin{tabular}{lccccccc} 
& CD13 & CD33 & CD34 & CD15 & CD45 & CD14 & CD41 \\
M0 & + & + & +++ & - & + & - & - \\
M1 & + & + & + & $-l+$ & + & - & - \\
\hline M2 & + & + & $+/-$ & +++ & + & - & - \\
M3 & + & + & $-/+$ & +++ & + & - & - \\
\hline M4 & + & + & $-/+$ & + & + & + & - \\
M5 & + & $+/-$ & + & + & + & +++ & - \\
\hline M6 & $-/+$ & $+/-$ & + & - & - & - & - \\
M7 & - & $+/-$ & + & - & - & - & +++ \\
\hline
\end{tabular}

Table 2. Four periods of AML7-3 protocol.

\begin{tabular}{|c|c|c|c|}
\hline Induction & Intensification 1 & Intensification 2 & Intensification $\mathbf{3}$ \\
\hline $\begin{array}{l}\text { Cytarabin } 100 \mathrm{mg} / \mathrm{m}^{2} / \text { day } \times 7 \text { days } \\
\text { Daunorubicin } 45 \mathrm{mg} / \mathrm{m}^{2} / \text { dayx3days. } \\
\text { BMA at day } 21 \text {. } \\
\text { If the patient does not achieve remission: } \\
\text { - Blast cells }>20 \% \text { : Cytarabine: } 2000 \mathrm{mg} / \mathrm{m}^{2} / 12 \text { hours } \times 6 \text { days. } \\
\text { - } 5 \%<\text { Blast cells }<20 \% \text { : Repeat cytarabine and daunorubicine as above }\end{array}$ & $\begin{array}{c}\text { Cytarabine } 1000 \mathrm{mg} / \mathrm{m}^{2} / 12 \\
\text { hours } \times 4 \text { days -Daunorubicine } \\
45 \mathrm{mg} / \mathrm{m}^{2} \times 3 \text { days }\end{array}$ & $\begin{array}{c}\text { Cytarabine } 2000 \mathrm{mg} / \mathrm{m}^{2 / 12} \\
\text { hoursx } 4 \text { days Etoposide } \\
100 / \mathrm{m}^{2} \times 4 \text { days. }\end{array}$ & $\begin{array}{c}\text { Repeat intensification } \\
1 \text { or } \\
\text { Cytarabine } 3000 \mathrm{mg} / \mathrm{m}^{2} / 12 \\
\text { hour } \times 3 \text { days. }\end{array}$ \\
\hline
\end{tabular}
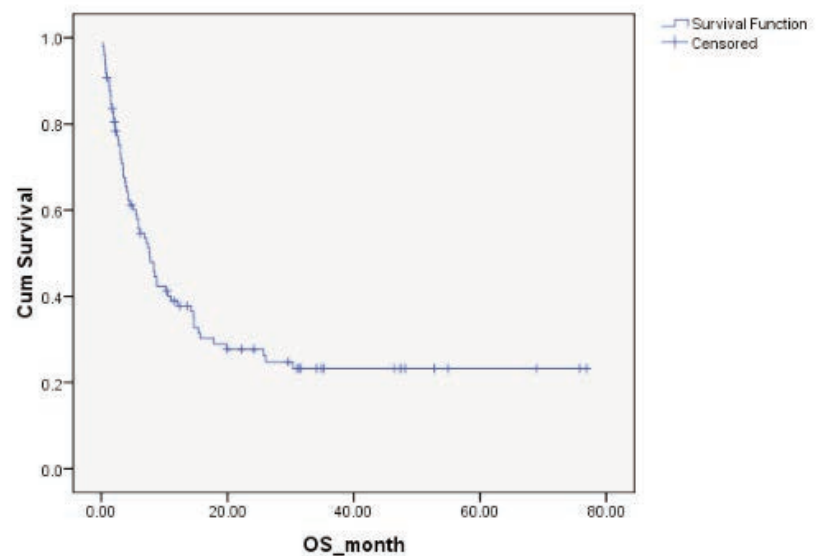

Figure 1. Overall survival curve.

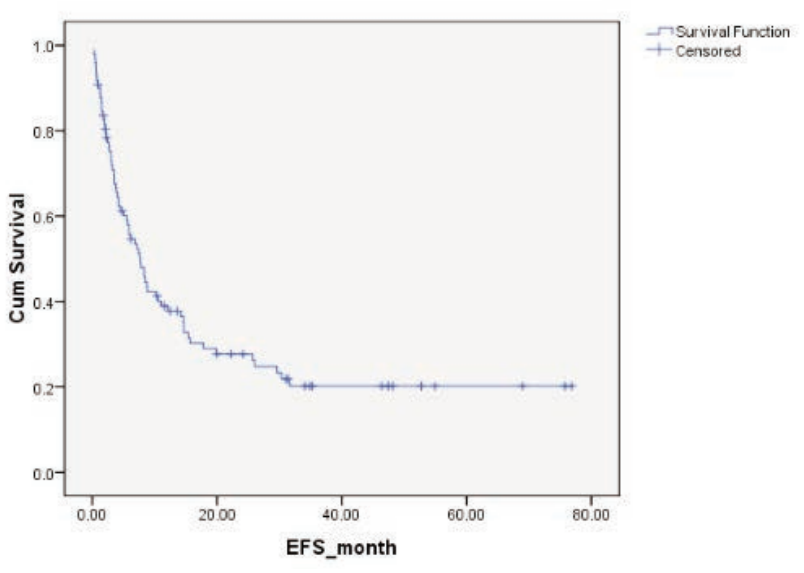

Figure 2. Even free survival curve 
factors, with the country's economic status being one contributor. With economic growth, children are more likely to have access to health insurance and to receive a timely diagnosis, high quality treatment, and supportive care, and parents are more likely to adhere to therapy, all of which contribute to improved survival rate of children with AML. 15 These things were true for my patients. Hemorrhagic, and infectious complications were also mainly causing of TRM (treatment related mortality). Sometime platelets and antibitotic, and antifungal were not enough or available in my center.

In the study of Jastaniah $\mathrm{W}, 16$ a total of 193 children diagnosed with de novo AML between January 2005 and December 2012 were identified, of those 175 were evaluable for outcome. The overall survival was $58.8 \pm 4 \%$ and event-free survival $40.9 \pm 4.1 \%$. Xu XJ et al. 13 report the outcome of childhood AML treated with modified National Protocol of Childhood Leukemia in China 1997 in a institution from 1997 to 2005. One hundred and eighty-five children with newly diagnosed AML were admitted. The 7-year overall survival and event free survival rates for the whole cohort were $33.1 \pm 4.1 \%$ and $31.2 \pm 3.7 \%$, respectively. Sixty patients (32.4\%) refused chemotherapy and 123 were eligible for protocol evaluation. Among eligible patients, 111 (90.2\%) achieved complete remission. The estimated 7-year OS and EFS rates were $50.2 \pm 5.5 \%$ and $46 . \pm 5.1 \%$, respectively. Acute promyelocytic leukemia (APL) was more curable than non-APL (7-year EFS: $63.5 \pm 7.9 \% \quad v s . \quad 35.9 \pm 6.3 \%, \quad \mathrm{P}=0.005)$. Thirty-one patients $(25.2 \%)$ relapsed, but no central nervous system leukemia was observed.

The best way to achieve a better outcome for childhood AML treatment is to improve compliance to treatment through an effective comprehensive program that includes: (a) parental education; (b) family affective management; (c) a patient tracking system; and, (d) social services for families (i.e., transportation, food and lodging subsidies). To meet international standards and improve treatment outcomes, we have completely applied the protocols AML7-3 for childhood AML.

The incidence of treatment abandonment has been reduced to $4.1 \%$ in the current study. This was obtained thanks to a strong intervention by Asian Children's Care League, which was able to classify the living conditions of patients at the time of diagnosis and to provide support, including a family food bag, money for travel, housing for parents, and other support as needed, together with a program for parents' education to improve their understanding of the disease, special care needs, administration of oral chemotherapy, etc. This result can be regarded as an exceptional

achievement and compares favorably with other contemporary experiences. ${ }^{17,18}$

The overall results from this study suggests that intensive therapy can be delivered

Table 3. Demographic characteristics of childhood acute myeloid leukemia by study period.

\begin{tabular}{|c|c|}
\hline Variables & ll case $(n=98)$ \\
\hline $\begin{array}{l}\text { Sex } \\
\quad \text { Male } \\
\text { Female }\end{array}$ & $\begin{array}{l}63(64.3 \%) \\
35(35.7 \%)\end{array}$ \\
\hline Mean age (range) & $5.56 \pm 3.19$ ( 3 months -15 years $)$ \\
\hline $\begin{array}{l}\text { Age, N (\%) } \\
\leq 1 \\
2-5 \\
5-9 \\
>9\end{array}$ & $\begin{array}{l}11(11.2) \\
39(39.8) \\
23(23.5) \\
25(25.5)\end{array}$ \\
\hline $\begin{array}{l}\text { Geography } \\
\text { Thua Thien Hue } \\
\text { Quang Tri } \\
\text { Other province }\end{array}$ & $\begin{array}{l}28 \\
20 \\
50\end{array}$ \\
\hline $\begin{array}{l}\text { Peripheral Blood } \\
\text { RBC }\left(\times 10^{12} / \mathrm{L}\right) \\
\text { Reticulocyte } \\
\text { Hemoglobin }(\mathrm{g} / \mathrm{L}) \\
\text { WBC }\left(\times 10^{9} / \mathrm{L}\right) \\
\text { Platelet count }(\times 109 / \mathrm{L}) \\
\text { Blast }\left(\times 10^{9} / \mathrm{L}\right)\end{array}$ & $\begin{array}{c} \\
3.27 \pm 0.63 \\
0.24 \pm 0.13 \\
85.12 \pm 14.11 \\
47.24 \pm 90.69 \\
65.25 \pm 70.20 \\
39.23 \pm 39.19\end{array}$ \\
\hline $\begin{array}{l}\text { Bone Marrow } \\
\text { Nuclear cells }(\times 109 / \mathrm{L}) \\
\text { \% Blast } \\
\text { Blast cell }(\times 109 / \mathrm{L})\end{array}$ & $\begin{array}{l}121.92 \pm 64.94 \\
66.20 \pm 21.39 \\
80.69 \pm 39.19\end{array}$ \\
\hline Abnormal Karyotyp $(\mathrm{n}=25)$ & \\
\hline $\begin{array}{l}\text { Hypodiploidy } \\
\text { Trisomy } 21 \\
\text { Hyperdiploidy }\end{array}$ & $\begin{array}{c}7(7.2) \\
5(5.1) \\
13(13.2)\end{array}$ \\
\hline $\begin{array}{l}\text { FAB classification (\%) } \\
M_{0} \\
M_{1} \\
M_{2} \\
M_{3} \\
M_{4} \\
M_{5} \\
M_{6} \\
M_{7}\end{array}$ & $\begin{array}{c}4(4.1) \\
21(21.4) \\
42(42.9) \\
0(0) \\
8(8.1) \\
16(16.3) \\
5(5.1) \\
2(2.1)\end{array}$ \\
\hline
\end{tabular}

Table 4. Treatment response.

\begin{tabular}{lcc} 
Variables & Number & Percentage \\
Treatment outcome & & \\
$\quad$ Complete remission & 61 & 62.2 \\
$\quad$ Partial remission & 13 & 13.3 \\
$\quad$ No remission & 13 & 13.3 \\
$\quad$ Death & 11 & 11.2 \\
After subsequent therapy & & \\
$\quad$ Achieve a complete remission & 20 & 76.9 \\
$\quad$ No remission & 6 & 23.1 \\
\hline Relapse (n=46) & & \\
$\quad$ During chemotherapy & 27 & 27.6 \\
$\quad$ After finishing chemotherapy & 19 & 19.4 \\
Abandonment & 4 & 4.1 \\
\hline
\end{tabular}


in a well organized center in an low $\square$ middle-income countries and that treatment abandonment can be reduced to a very low incidence with promising results. However, these results remain suboptimal because of the socioeconomic conditions that are associated with a higher risk of late diagnosis and early death. Longer follow-up also is needed to determine whether a plateau at 5 years has been reached with this therapy. Further improvement in survival should be pursued through educational programs to facilitate earlier diagnosis, better management of infectious complications, better knowledge of the disease, and possibly different treatment strategies.

\section{Conclusions}

Abandonment has been reduced successfully with holistic strategies such as financial support, managing family group, providing education, early follow-up of patients who missed appointments and free accommodation near hospital for patients/ families.

With our efforts to providing less toxic modified protocol to reduce the death. However, with a high rate patient achieved complete remission after induction phase $(82.6 \%)$, but the overall survival and eventfree survival at 3 years were still low in my hospital (23.2\% and $20.2 \%$ respectively). It reflected that it was very difficult to treat successfully AML in low- and middleincome countries. We are considering the way how to improve the quality treatment for childhood acute myeloid leukemia in my hospital. How to improve supportive care to reduce infection, compose standard protocol for febrile neutropenia, so we could treat infection more effectively and could provide chemotherapy on time. In addition, management of pain and end-oflife care are the essential components of palliative care to support for patients who are not curable.

\section{References}

1. Gamis AS, Alonzo TA, Perentesis JP, et al. Children's Oncology Group's 2013 blueprint for research: acute myeloid leukemia. Pediatr Blood Cancer 2013;60:964-71.

2. Horibe K, Saito AM, Takimoto T, et al. Incidence and survival rates of hematological malignancies in Japanese children and adolescents (2006-2010): based on registry data from the Japanese Society of Pediatric Hematology. Int J Hematol 2013;98:7488.

3. Komur M, Erbey F, Bayram I, Tanyeli A. Incidence and prognostic importance of molecular genetic defects in children with acute myeloblastic leukemia. APJCP 2010;11:1393-5.

4. Grimwade D, Walker H, Oliver F, et al. The importance of diagnostic cytogenetics on outcome in AML: analysis of 1,612 patients entered into the MRC AML 10 trial. The Medical Research Council Adult and Children's Leukaemia Working Parties. Blood 1998;92:2322-33.

5. Bals E, Kaspers GJ. Treatment of childhood acute myeloid leukemia. Exp Rev Anticancer Ther 2005;5:917-929.

6. Ward E, DeSantis C, Robbins A, et al. Childhood and adolescent cancer statistics, 2014. Cancer J Clin 2014;64:83103.

7. Viana MB, Cunha KC, Ramos G, Murao M. [Acute myeloid leukemia in childhood: 15-year experience in a single institution]. Jornal de pediatria 2003;79:489-96.

8. Imamura T, Iwamoto S, Kanai R, et al. Outcome in 146 patients with paediatric acute myeloid leukaemia treated according to the AML99 protocol in the period 2003-06 from the Japan Association of Childhood Leukaemia Study. Br J Haematol 2012;159:204-10.

9. Creutzig U, van den Heuvel-Eibrink MM, Gibson B, et al. Diagnosis and management of acute myeloid leukemia in children and adolescents: recommendations from an international expert panel. Blood 2012;120:3187-205.

10. Creutzig U, Zimmermann M, Ritter J, et al. Treatment strategies and long-term results in paediatric patients treated in four consecutive AML-BFM trials. Leukemia 2005;19:2030-42.

11. Sandahl JD, Kjeldsen E, Abrahamsson J, et al. Ploidy and clinical characteristics of childhood acute myeloid leukemia: A NOPHO-AML study. Genes Chromosomes Cancer 2014; 53:667-75.

12. Dama E, Pastore G, Mosso ML, et al. Time trends and prognostic factors for survival from childhood cancer: a report from the Childhood Cancer Registry of Piedmont (Italy). Eur J Pediatr 2006; 165:240-9.

13. Xu XJ, Tang YM, Song H, et al. Longterm outcome of childhood acute myeloid leukemia in a developing country: experience from a children's hospital in China. Leukem Lymphom 2010;51:2262-9.

14. Wiangnon S, Veerakul G, Nuchprayoon I, et al. Childhood cancer incidence and survival 2003-2005, Thailand: study from the Thai Pediatric Oncology Group. Asian Pac J Cancer Prev 2011;12:2215-20.

15. Chow EJ, Puumala SE, Mueller BA, et al. Childhood cancer in relation to parental race and ethnicity: a 5-state pooled analysis. Cancer 2010; 116:3045-53.

16. Jastaniah W, Al Ghemlas I, Al Daama S, et al. Clinical characteristics and outcome of childhood de novo acute myeloid leukemia in Saudi Arabia: A multicenter SAPHOS leukemia group study. Leukem Res 2016;49:66-72.

17. De Pernillo M, Rivas S, Fuentes L, et al. Measurement of socio-economic status in families of children with cancer in Guatemala. Pediatr Blood Cancer 2014; 61:2071-3.

18. Navarrete M, Rossi E, Brivio E, et al. Treatment of childhood acute lymphoblastic leukemia in central America: a lower-middle income countries experience. Pediatr Blood Cancer 2014;61: 803-9. 